\title{
PROJECT OF AN EXPERIMENTAL SIMULATOR DESIGNED TO ANALYSE PESTICIDE SPRAYING TECHNIQUES IN VINEYARD USING DRONES
}

\author{
Terenziano Raparelli ${ }^{1}$, Gabriella Eula ${ }^{1}$, Alexandre Ivanov ${ }^{1}$, Giuseppe Pepe ${ }^{1}$ \\ ${ }_{1}^{1}$ Department of Mechanical and Aerospace Engineering, Politecnico di Torino, Torino, 10129, Italy \\ Email: gabriella.eula@polito.it
}

\begin{abstract}
This paper presents the study and the project of an innovative experimental simulator useful to experiment pesticide spraying techniques in vineyard using drones. The project was about: the study of the hydraulic circuit used to spray the pesticide, the drone characteristics, the vineyard characteristics and dimensions. This experimental simulator allows to modify and to test the flight height of the drone from the soil, the advancement velocity of the drone, the effect of the drone rotors, the number and the position of the spraying nozzles, their supply pressure and flowrate, using an original and innovative vineyard simulator designed by the authors. The dimensions of the experimental simulator is suitable to use it in a laboratory. The control of this experimental simulator was designed following a specific flowchart that allows preliminary to configurate the bench and to carry out the tests. The vine leaves were simulated using hydro sensible papers or real vine leaves. Using both these solutions authors want to test the performance of the hydraulic circuits and the distribution of the droplets in the crop. The vineyard is simulated with a structure designed in real scale (1:1), whose dimensions was obtained from a real crop. This structure allows to change the collocation of the devices used to test the hydraulics circuits and simulating the vine leaves.
\end{abstract}

Keywords: Pesticide spraying techniques using drones, Nozzles to spray pesticide in vineyard, Treatment of the vineyard using drones, Pesticide spraying circuits for vineyard, Drones in agriculture.

\section{Introduction}

The use of innovative technologies, in particular drones, in agriculture has influenced a lot of operations and treatments, such as the pesticide spraying techniques [14-21].

The spraying techniques of pesticide in vineyard using drones has some advantages in comparison with the traditional atomizers tractors.

In fact the drones allow to avoid to compact the soil, to change the spraying height from the soil and on the crop, to fly with lower height than helicopter or aeroplane used in agriculture [12-19, 9-21], so reducing the pesticide dispersion in the environment and improving the crop treatment.

An easy variation of the drone flight and so of the spraying trajectories, the possible various layouts of the nozzles under the drone, the reduction of the time for the refill of the system, the development and the test of this new technology can be some of the aspects to investigate $[11,14,15]$.

In literature $[15,16]$ some test benches are presented with this purpose, but generally they study and experiment the single nozzle or some spraying systems for atomizer tractors.
Often numerical models in specific software environments were realised to analyse the spraying conditions using drones [8,18,29]. So the experimental simulator prototype here presented is innovative both in its configuration and in its purpose.

In the past in the Department of Mechanical and Aerospace Engineering (DIMEAS) of the Politecnico di Torino (Italy) a lot of studies were carried out in order to test automatic systems applied in agriculture, such as innovative automatic machines for fruit harvest [2, 3], tomato grafting [7], systems to spray pesticide in a safe conditions in the greenhouses [4-6], the analysis of the three point hitch mechanism for tractors [23] and of the rotary harrow implement [22, 24, 25].

Nowadays, during a Research Project (PRIN2017 - Relevant National Interest Research Projects, "New technical and operative solutions for the use of drones in Agriculture 4.0"), in DIMEAS (Politecnico di Torino) the design of an innovative experimental simulator capable of simulating the pesticide spraying in a vineyard using drones was developed. 
This paper illustrates the project of this experimental simulator with also the realisation of the vineyard in a software environment.

This experimental simulator is interesting to test all the parameters involved during the pesticide spraying in the vineyard using drones, such as: to modify and to test the distance of the drone from the soil, to analyse the effect of the drone advancement velocity, of the drone rotors, of the types, number and position of the spraying nozzles, of their supply pressure and flowrate for the droplets generation, using an original and innovative vineyard simulator designed by the authors. The dimensions of this experimental simulator are suitable to use the system in a laboratory. If it is necessary, it can be also used in a wind tunnel for tests analysing drift phenomena on the sprayed jets. The advantages to use an experimental simulator are that all the spraying parameters and conditions can be preliminary tested and optimised in a safe situation for the operator and for the environment, evaluating with precision and repeatability the characteristics of the circuit and of the pesticide spraying techniques. Furthermore, this prototype has a modular construction, so it can be configured in order to examine a lot of possible spraying conditions on the crop.

\section{Development of the Vineyard in a Software Environment}

Authors obtained a lot of important and interesting information from agricultural operators, that gave all the dimensions of a typical Italian vineyard. Using these dimensions, a complete scheme of a vineyard was reproduced using a commercial CAD software in 1:1 scale. This model is important to study the position of the drone and of the spraying nozzles on the vineyard and then to realise a simulator of the vineyard in the experimental simulator developed.

In the Figures 1 the vineyard model realised by the authors in a software environment is illustrated. The Figures 1a and b show an axial and a frontal view of the vineyard model.

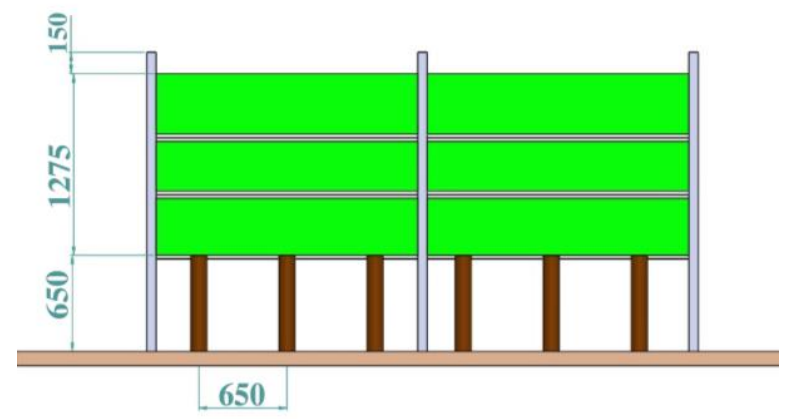

a)

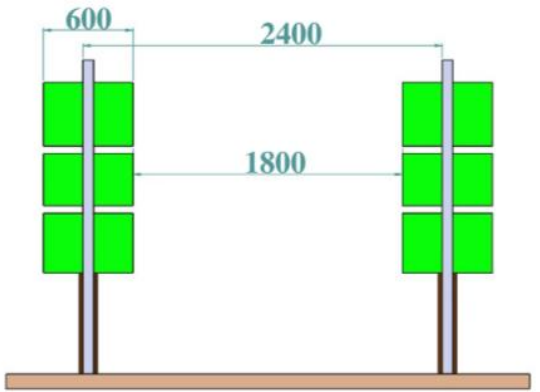

b)

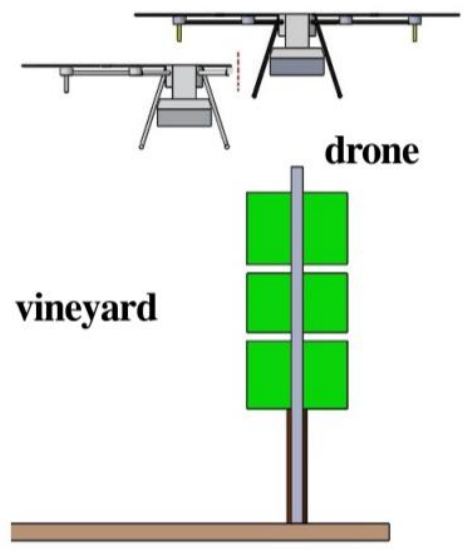

c)

Figure 1: Study of the vineyard (dimensions in $\mathrm{mm} ; 1$ $\left.\mathrm{mm}=10^{-3} \mathrm{~m}\right):$ a) vineyard model reproduce in the software (axial view); b) vineyard model frontal view; c) possible positions of the drone on the vineyard or on the row

Using this vineyard model some considerations on the drone position on the crop could be tested, as shown in the Figure 1c, useful for the experimental simulator design [26].

\section{Design of the Hydraulic Circuit}

The hydraulic circuit here considered is made of: a tank, a filter, a pump, some pipelines to connect the components, the spraying nozzles, a pressure transducer, flowmeters. A pressure reducer is put upstream the nozzles to select and to guarantee their supply pressure during the test. An electronic board can be used to manage this circuit.

The spraying nozzles were studied analysing different types and numbers. Various positions of these components were investigated in order to find the more suitable nozzles types, number and layout to treat properly the crop. These considerations were preliminarily carried out using the vineyard model realized in a software environment, where the geometry nozzles jets were drawn and investigated, considering always a suitable distance of the drone from the crop. 
So analysing a lot of catalogues of spraying nozzles, authors selected some types of nozzles suitable for this application [28].

Their choice was done considering: the geometry of the jet (a flat jet or a cone ject, full or not); the supply pressure; the flowrate required in order to obtain droplets suitable to be used in an open environment avoiding drift phenomena (from 130 to $400 \mu \mathrm{m}$ in diameters); the dimensions and the weight, in order to reduce the load on the drone; their functioning characteristics in comparison with the selected pump.

The Figure 2a shows an example of a possible nozzles layout, illustrating one of the evaluations done to study the number and the position of the nozzles.

In particular authors also carried out the project of some little bars to connect under the drone in order to position lower some nozzles, treating in this way, simultaneously, the inferior part of the crop.

In the Figure $2 \mathrm{~b}$ a schematic drawing of the hydraulic circuit is shown.

The dimensions of the tank was also established in order to have few flights of the drone and a low load to transport.

The pump was selected analysing its characteristic (compared with the nozzles ones), its weight, its dimension.

The Figure 2c shows an example of some characteristics of the possible suitable nozzles, compared with the pump one, in order to identify the components characteristics and the functioning points for this circuit. An example of components suitable for the circuit are: a tank about $10 \mathrm{l}\left(1 \mathrm{l}=10^{-}\right.$ ${ }^{3} \mathrm{~m}^{3}$ ); a filter; a pump; four nozzles with a cone jet (open angle $80^{\circ}$ ), supply pressure variable from 2 to $6 \mathrm{bar}$, flowrate variable for example (for a single nozzle) from $0,65 \mathrm{l} / \mathrm{min}\left(1,08^{*} 10^{-5} \mathrm{~m}^{3} / \mathrm{s}\right)$ to 1,10 $1 / \min \left(1,83^{*} 10^{-5} \mathrm{~m}^{3} / \mathrm{s}\right)$, droplet dimensions from 130 to $400 \mu \mathrm{m}$; a pressure reducer to select and to guarantee the nozzles supply pressure; a pressure transducer; flowmeters.

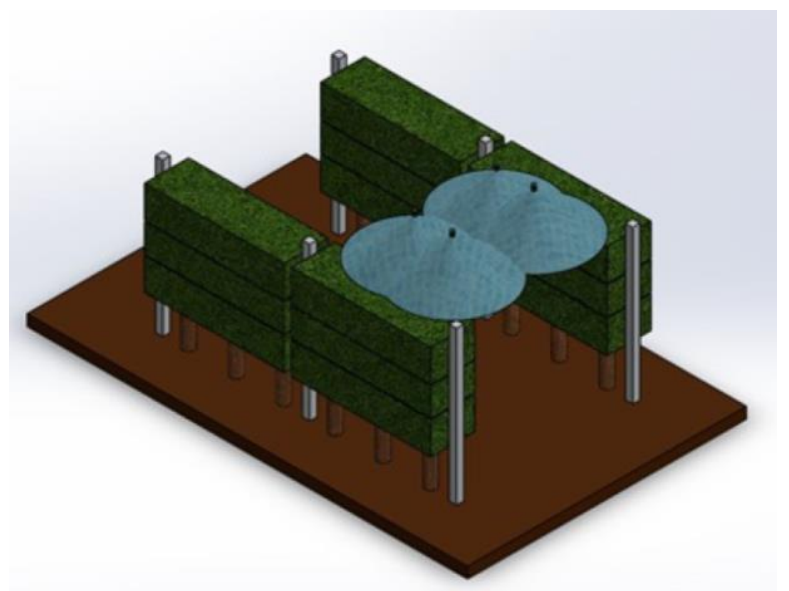

a)

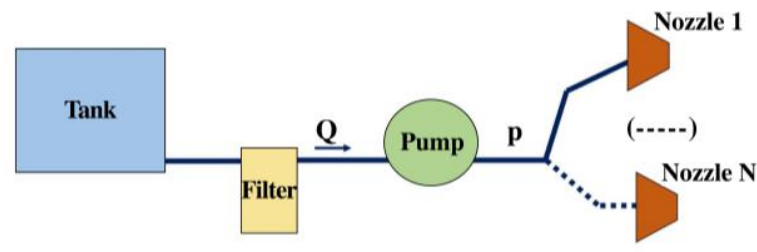

b)

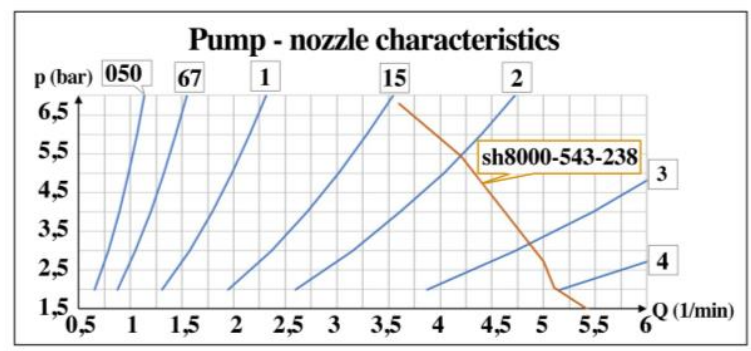

c)

Figure 2: Nozzles analysis: a) one of the nozzles configuration analysed; $b$ ) the hydraulic circuit scheme; c) nozzles and pump functioning characteristics $\left(1 \mathrm{bar}=10^{5} \mathrm{~Pa} ; 1 \mathrm{l}=10^{-3} \mathrm{~m} ; 1 \mathrm{~min}=\right.$ 60s)

In the Figure $2 \mathrm{c}$ the meaning of the numbers on the nozzles characteristics $(050,67,1,15,2,3.4)$ are referred to the specific models of nozzles from the manufacturer catalog (for example TXA800*VK TeeJet Technologies - U.S.A. nozzle) while the pump model sh8000-543-238 is from China Shurflo manufacturer - China. Anyway, the experimental simulator prototype here presented obviously allows to test different types, numbers and positions of nozzles and pumps.

\section{Design of the Experimental Simulator}

The experimental simulator was designed realising in it: a vineyard simulator; the spraying circuit; a moving system simulating the drone advancement and carrying on the spraying circuit; some fans simulating the drone rotors; a lot of possible movements and adjustments to test different spraying conditions. The Figure 3 illustrates a preliminary scheme of the experimental simulator here examined.

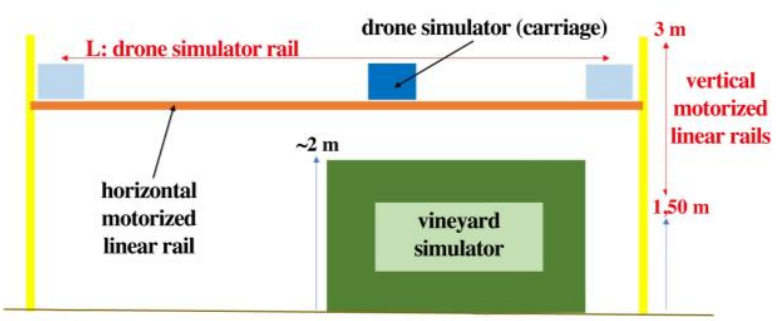

Figure 3: A preliminary scheme of the experimental simulator prototype (scheme not in scale) 
Using the scheme of Figure 3 it was possible to understand the various parts and the movements required in the experimental simulator prototype.

The Figure 4 shows the whole experimental simulator prototype, where there are: the vineyard simulator 1); the drone simulator 2) (the hydraulic circuit, not evidenced in the figure, is hung under this carriage); the fans 3) simulating the drone rotors; the horizontal electrical rail 4); the vertical electrical rails 5).

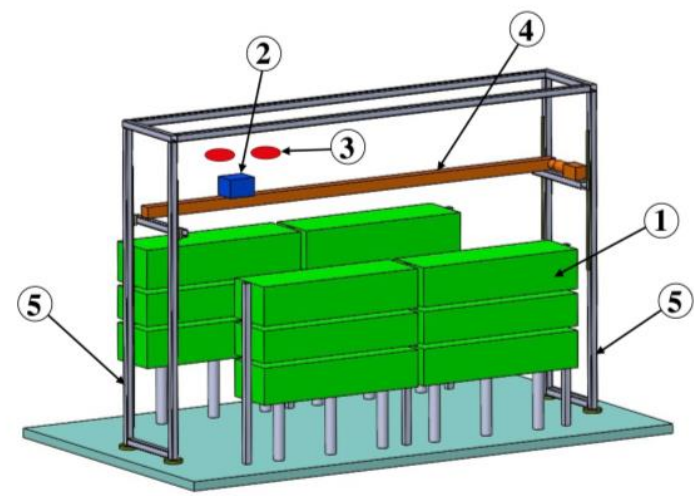

Figure 4: The experimental simulator prototype

Here as follows the various parts of the experimental simulator were described.

\section{- Vineyard simulator}

Some evaluations were done by the authors in order to understand the characteristics of this crop and to reproduce it properly in the experimental simulator. In the Figures 5 some considerations on a real vineyard branch (a) and on a vine leaf (b) were presented. In the experimental simulator these parts can be simulated using real vine leaves to reproduce both the vine leaf and its stem with their dimensions, ridge and flexibility. In addition to these real vine leaves, authors want to use some hydro sensible papers put on the vineyard simulator in order to study the droplets dimensions and their distribution.

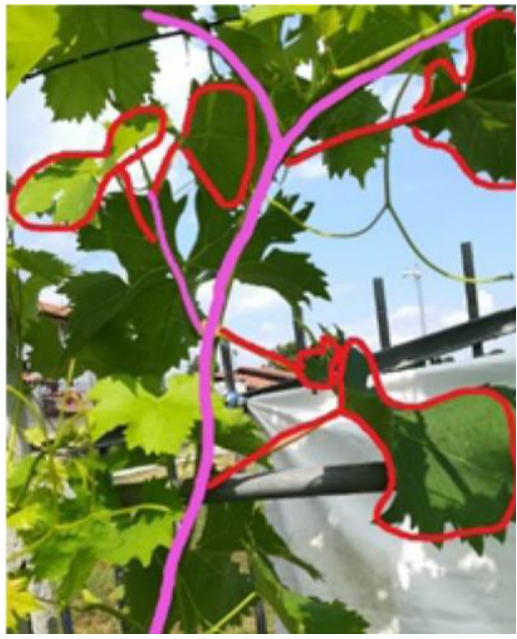

a)

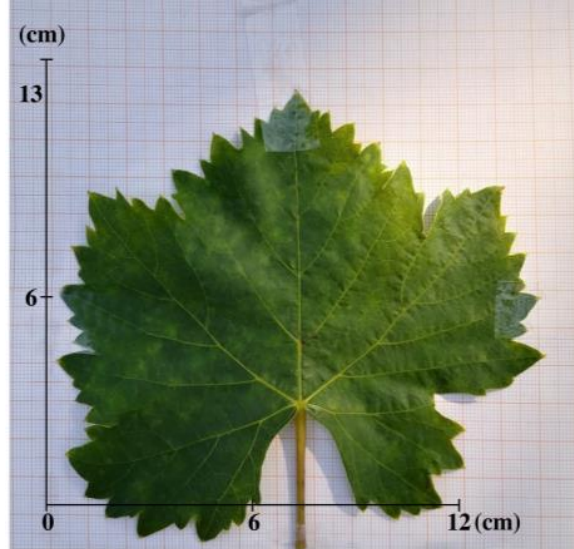

b)

Figure 5: Analysis useful to reproduce the vineyard in the experimental simulator: a) vine branches; $b$ ) vine leaf $\left(1 \mathrm{~cm}=10^{-2} \mathrm{~m}\right)$

The vine crop grows developing branches. The herbaceous branches and the shoots with the leaves start from the woody trunk.

The shoots have stiffness and they cannot be easily flexed till to reach the open extremities. These have length equal to $50-100 \mathrm{~cm}\left(1 \mathrm{~cm}=10^{-2} \mathrm{~m}\right)$. The branches have a diameter of $8-10 \mathrm{~mm}$ near the vine shoot and of $6 \mathrm{~mm}$ in the peripheral areas $(1 \mathrm{~mm}=$ $10^{-3} \mathrm{~m}$ ).

The leaves have an equivalent diameter generally from $5-6 \mathrm{~cm}$ to $10-13 \mathrm{~cm}$ with an area of $100 \mathrm{~cm}^{2}$. They have a high flexibility.

Using also the previous information on the vineyard dimensions, a simulator of the vineyard was studied for this prototype, as shown in the Figure 6.

It is designed in 1:1 scale and it is made of some vertical rigid elements among with some metallic horizontal crossbeams were positioned. On them or hydro sensible papers or the real vine leaves and stems can be collocated.

This vineyard simulator allows to change, if it is necessary, the distance of the horizontal crossbeams from the soil or among themselves and to test the effect of the treatment in the canopy of the crop, putting the hydro sensible papers (or the real vine leaves) in various positions on these horizontal flat surfaces.

In this way the spraying performance can be tested analysing various vineyard conditions.

The analysis of the experimental results can be carried out using a microscope, to see the droplets dimensions and distribution on the crop.

The effect of the drone rotors on the movement of the vine leaves during the drone advancement or on the droplets distribution can be analysed by means of some fans put on the spraying circuit during the experimental tests.

Using a high-speed video camera, the sprayed jets and the droplets distribution can be directly analysed during the experimental tests. 


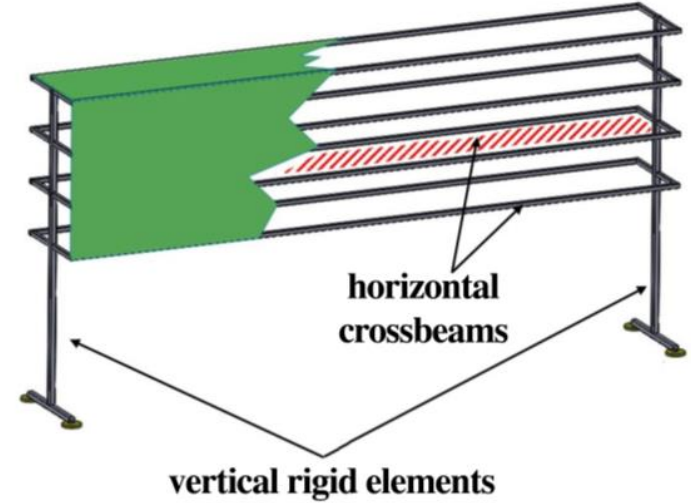

Figure 6: Parts simulating the vineyard in the prototype here presented

\section{- Drone simulator}

In the experimental simulator here presented the drone was simulated by means of a carriage moved with an electrical linear rail capable of transporting the spraying circuit along a horizontal axis, simulating the advancement of the drone.

The vertical distance from the soil can be changed moving the horizontal crossbeam along vertical elements, collocated in the corners of the experimental simulator.

This movement can also be done using electrical linear rails.

The vertical positioning of this horizontal crossbeam can be established using or a wired position transducer or a graduated scale, to decide the vertical distance from the soil of the spraying circuit in the first steps of the working cycle foreseen for the experimental simulator.

The Figure 7 shows some more details of this prototype.

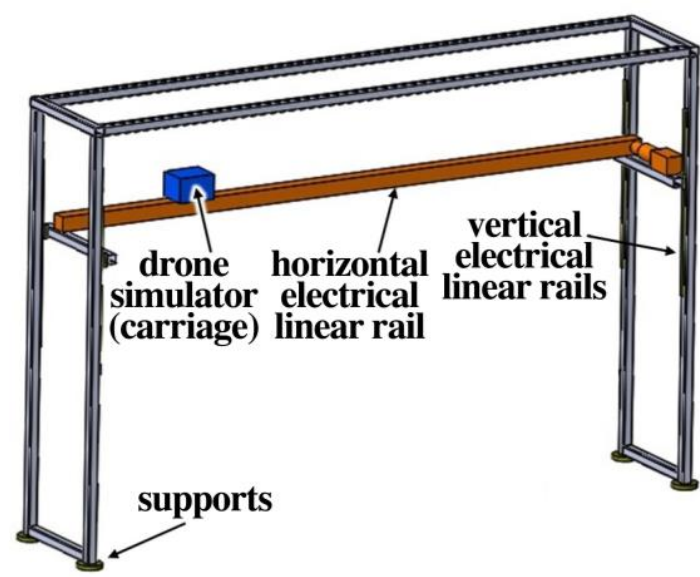

Figure 7: Some more details of the experimental simulator

The type of the drone here considered, as an example, has the following technical characteristics:
8 rotors; maximum payload $10 \mathrm{~kg}$; maximum advancement velocity $8 \mathrm{~m} / \mathrm{s}$; working distance from the soil $2 \div 3,5 \mathrm{~m}$.

To analyse the effect of the drone rotors, both on the droplets distribution and on the vine leaves movement, two or more fans were foreseen on the carriage (for example SPAL AUTOMOTIVE - Italy, VA18-AP10/C-41S, $13 \mathrm{~kg}$ each, flowrate $1870 \mathrm{~m}^{3} / \mathrm{h}$ each, electrical supply $12 \mathrm{~V} \mathrm{dc}$ ). In fact, it is known that with the common atomizer tractors there is an opportune effect on the pesticide spraying conditions from the movement of the vine leaves generated by the tractor fan.

In the Figure 8 the velocity behaviour during the carriage movement was analysed, referred to the vineyard simulator: in this picture an example of hydro sensible papers use is presented. The carriage movement has an initial and a final acceleration and a movement with a constant velocity, as shown in the Figure 8. This analysis is useful to establish properly the position of the hydro sensible papers or of the sample of the vine leaves during the movement of the carriage in the vineyard simulator.

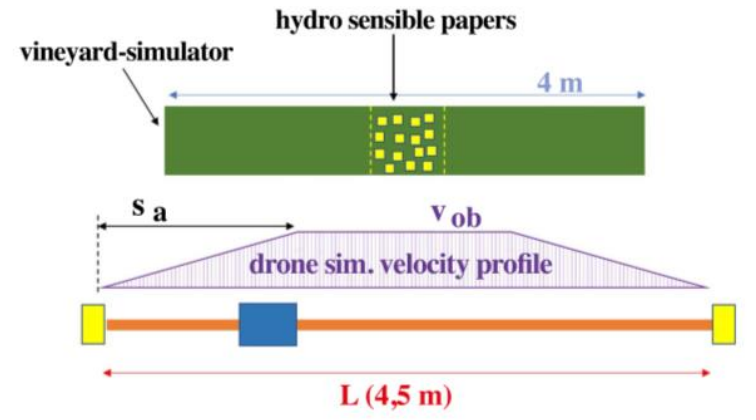

Figure 8: Analysis of the movement of the carriage simulating the drone

With the hypothesis of a constant acceleration during the carriage movement, the distance $s_{a}$ in different velocity conditions was calculated. In particular this analysis is done, as an example, with the values of accelerations and velocities expressed in the Table 1, where $s_{a}$ is the distance in the Figure $8\left(1 \mathrm{~cm}=10^{-2} \mathrm{~m}\right) ; \mathrm{a}$ is the acceleration; $\mathrm{v}_{\mathrm{ob}}$ is the velocity.

Table 1. Evaluations for the carriage movement law

\begin{tabular}{|c|c|c|c|c|c|}
\hline \multirow{2}{*}{\multicolumn{2}{|c|}{$\mathrm{S}_{\mathrm{a}}(\mathrm{cm})$}} & \multicolumn{4}{|c|}{$\mathrm{V}_{\mathrm{ob}}(\mathrm{m} / \mathrm{s})$} \\
\hline & & 2 & 4 & 6 & 8 \\
\hline \multirow{4}{*}{ 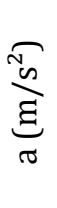 } & 5 & 40 & 160 & 360 & 640 \\
\hline & 10 & 20 & 80 & 180 & 320 \\
\hline & 20 & 10 & 40 & 90 & 160 \\
\hline & 30 & 7 & 27 & 60 & 107 \\
\hline
\end{tabular}

Using these considerations the distances $\mathrm{s}_{\mathrm{a}}$ (Figure 8) for the design of the experimental 
simulator can be evaluated. In particular it can be noticed that the velocities 6 and $8 \mathrm{~m} / \mathrm{s}$ require a more length of the horizontal crossbeam.

In this experimental simulator it is also possible to simulate the drone flight both on the row (Figure 9a) and directly on the crop (Figure 9b), manually moving the vineyard simulator.

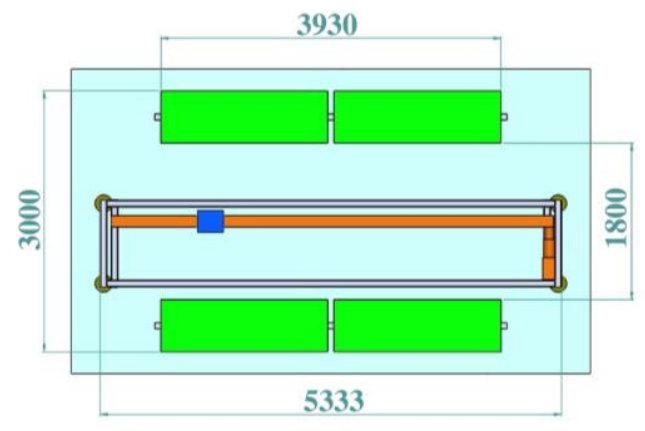

a)

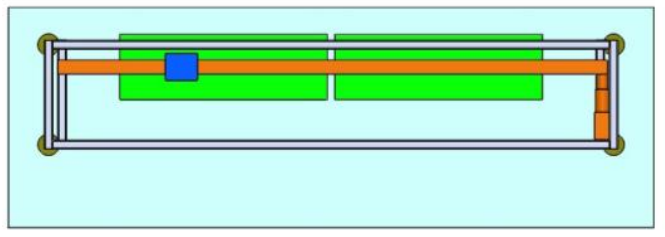

b)

Figure 9: Some possible layouts of the experimental simulator (dimensions in $\mathrm{mm} ; 1 \mathrm{~mm}=$ $10^{-3} \mathrm{~m}$ ): a) carriage simulating the drone on the row;

b) carriage simulating the drone on the crop

\section{- The control system of the experimental simulator}

This experimental simulator has some electrical sources to supply the required movements and the hydraulic circuit.

An example of working cycle is illustrated by means of the flowchart shown in the Figure 10.

In this flowchart the first step is the analysis of the position of the movable components and their positioning in the start configuration.

The status of the tank is also evaluated, starting the working cycle only if the tank is full.

Then the distance from the soil of the spraying circuit is selected and also the position of the drone simulator, on the top or on the row of the crop, is established.

After this, the fans are switched on and then the hydraulic circuit is supplied.

In these conditions the carriage simulating the drone is moved horizontally, carrying out the spraying step.

When the tank is empty, the system is stopped and prepared for a next working cycle.

This working cycle is managed using a PLC, for example Micro $800 \mathrm{Cpu} 820$ Allen-Bradley Italia (Rockwell Automation - U.S.A.) 24V dc.
In particular in this experimental simulator the following components can be foreseen:

1) an electrical linear rail (for example FESTO Germany - Positioning drives ELGA - TB - RF or other suitable models) to move horizontally the carriage simulating the advancement of the drone, using a proper system to select, for each test, the velocity value;

2) one (or two, if it is necessary) electrical linear rails (for example FESTO - Germany - Positioning drives EGC - 120 - $3000-\mathrm{TB}-\mathrm{KF}-\mathrm{OH}-\mathrm{GK}$ ) to position vertically the spraying circuit, simulating different distances of the drone from the soil;

3) the electronic board for the hydraulic circuit;

4) electrical sources to supply the PLC, the fans, the hydraulic circuit and the electrical linear rails.

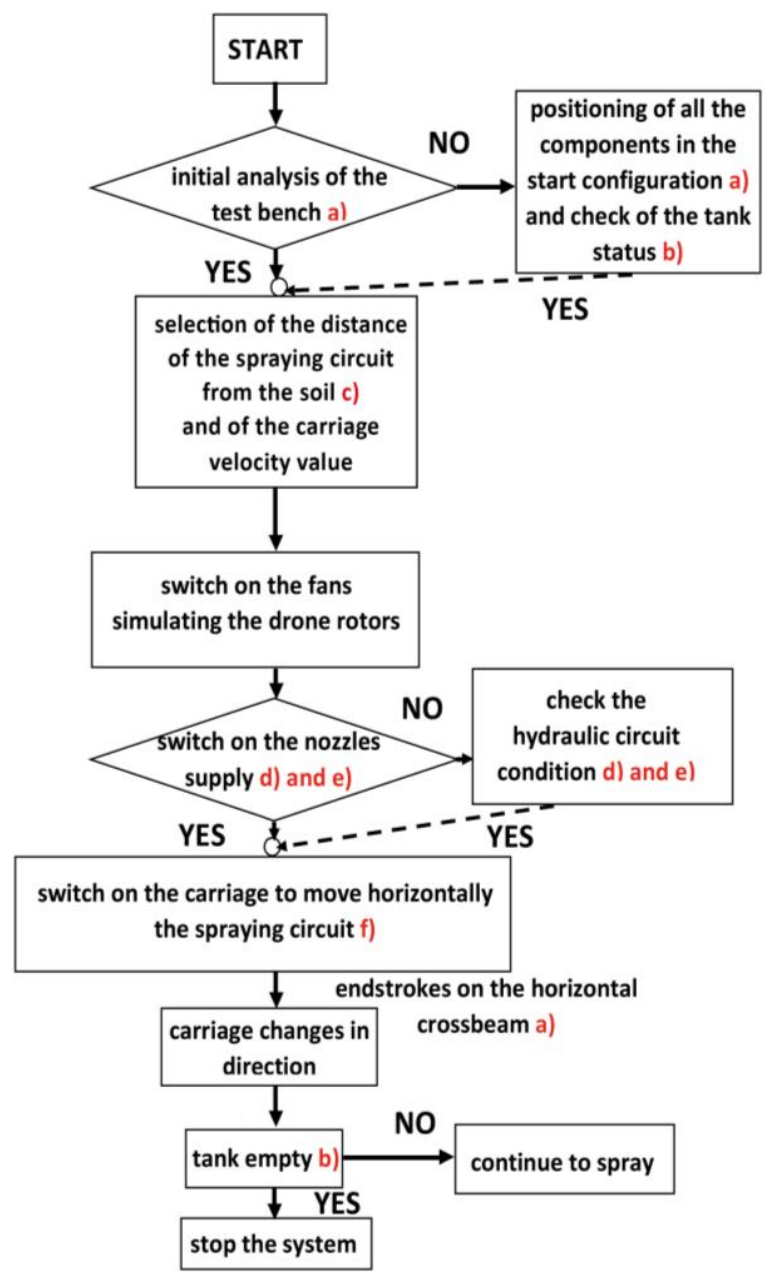

Figure 10: An example of flowchart used to control this experimental simulator

The sensors suitable for this flowchart could be:

a) standard electrical endstroke switches, directly put in the electrical linear rails;

b) a load cell put between the rigid part of the drone (here the carriage) and the hung tank (for example SA15 LAUMAS ELETTRONICA Italy); 
c) a wired position transducer or a visible graduated scale put on the vertical elements (for example the sensor WPS-5000-MK88 from Micro-Epsilon Measurement Technology Management Company Group - Germany);

d) a pressure transducer (for example RS PRO 8285745 pressure transducer for water from RS Components - Italy);

e) a flowmeter (for example RS PRO Turbine Flow Meter 5082704 flowmeter for water from RS Components - Italy);

f) an optical scale (for example RSLA from RENISHAW Italy) to measure the velocity of the carriage simulating the drone.

The indications a) b) c) d) e) f) also illustrate the various types of sensors in the flowchart shown in the Figure 10.

To analyse the spraying conditions a high-speed video camera (for example Sony FDR-AX700 video camera - Japan) can be used [20].

Furthermore, a proper acquisition data system (for example the Global Sizing Velocimeter from TSI Incorporated - U.S.A.) can be foreseen in this experimental simulator.

To analyse a possible autonomous search of the crop points to treat, also a suitable vision system can be added in the experimental simulator.

Comparing this experimental simulator with studies on the pesticide spraying circuits shown in literature [14-26], it is possible to underline the innovative and original characteristics of this prototype. It has a modular design and it allows to test in laboratory different pesticide spraying circuits on a vineyard using a drone.

\section{Conclusions}

In this paper the design of an innovative experimental simulator capable of simulating the pesticide spraying in a vineyard using a drone is presented.

Its main advantage is the possibility to test preliminary in laboratory all the spraying parameters and conditions, working in a safe situation for the operator and for the environment.

The prototype is adaptable and gives the possibility to change a lot of parameters and dimensions. Its modular construction allows to realise it in various configurations, to use in it various types of commercial components and so to investigate a high number of spraying conditions, giving the possibility to obtain a complete knowledge about this application. The vineyard study and simulator is also an original and new aspect of this prototype.

In the future authors will start to construct some parts of this experimental simulator in order to investigate experimentally the functioning of these spraying conditions.
Authors also want to investigate the main characteristics of the vine leaves and stems (such as geometry, dimensions, roughness, porosity, furry, stiffness, etc...) in order both to find equivalent and suitable artificial materials useful to construct artificial vine leaves models to use in this experimental simulator and to improve the spraying droplets distribution, knowing the vine leaves characteristics.

\section{Acknowledgements (not mandatory)}

The research is financed by means of MIUR funds PRIN2017 (Relevant National Interest Research Projects) "New technical and operative solutions for the use of drones in Agriculture 4.0".

Authors thank Eng. M.Persico, Eng. N. Filippi, Eng. P. Gala, Eng. E. D'Alo' for their help during the study.

Authors thank the family M. Martinelli "Antica Meridiana Relais-Art" vineyard - Vicoforte (CN Italy) for their help in the crop dimensions analysis.

\section{References}

[1] Ahirwar S., Swarnkar R., Bhukya S., Namwade G.; Application of drone in agriculture, International Journal of Current Microbiology and Applied Sciences, Volume 8, Issue 1, Pp: 2500-2505, 2019.

[2] Belforte G., Eula G., Nieddu F., Raparelli T., Turco G., Automatic fruit harvesting devices, Management and technology applications to empower agricolture and agro-food systems, XXX CIOSTA-CIGR V CONFERENCE, 22-24th September, Grugliasco Italy, Pp: 347-356, 2003.

[3] Belforte G., Eula G., Raparelli T., Turco G., Automatic table grape and kiwifruit harvester, IMG04 Conference Proceedings, 1-2nd July, Genova Italy, Pp: 259-265, 2004.

[4] Belforte G., Eula G., Raparelli T; Analysis of Pneumatic Techniques for Pesticide Spraying in Greenhouses, Experimental Techniques, Volume 33, Issue 6, Pp: 21-29, 2009.

[5] Belforte G., Eula G., Raparelli T.; DeVoPeS: Defined Volume Pesticide Sprayer design and testing, Experimental Techniques, Volume 35, Issue 6, Pp: 14-26, 2011.

[6] Belforte G., Eula G., Raparelli T.; A new technique for safe pesticide spraying in greenhouses, Pesticides: formulations, effects, fate: $8^{\text {th }}$ Chapter Book, Intechweb, ed. Margarita Stoytcheva, Pp: 129-154, Published: 2011.

[7] Belforte G., Eula G., Raparelli T., Sirolli S., Piccarolo P., Gay P., Ricauda Aimonino D., Comba L., Preliminary design of an electropneumatic automatic machine for herbaceous grafting, Mechanisms and Machine Science - Advances in Service and Industrial Robotics - Proc. of the $26^{\text {th }}$ International Conference on Robotics in 
Alpe - Adria - Danube Region RAAD 2017, 2123rd June, Torino Italy, Springer International Publishing, Volume 49, Pp: 255-263, 2018.

[8] Bylesjo M., Segura V., Soolanayakanaholly R.Y., Rae A.M., Trygg J., Gustafssan P., Jansoon S., Stree N.R.; LAMINA: a tool for rapid quantification of a leaf size and shape parameters, BMC Plant Biology, Volume 8, Issue 82, Pp: 1-9, 2008.

[9] Capello C., Biddoccu M., Ferraris S., E. Cavallo; Effects of Tractor Passes on Hydrological and Soil Erosion Processes in Tilled and Grassed Vineyards, Water, MDPI, Volume 11, Issue 10, Pp: 2-25, 2019.

[10] Faical B.S., Freitas H., P.Ganes P.H., Mano L.Y., Pessin G., De Carvalho A.C.P.L.F., Krishnamachari B., Ueyama J.; An adaptive approach for UAV-based pesticide spraying in dynamic environments, Computers and Electronics in Agriculture, Volume 138, Pp: 210 223, 2017.

[11] Forney S.H., Luck J.D., Kocher M.F., Pitla S.; Laboratory and full boom-based investigation of nozzle setup error effects on flow, pressure, and spray pattern distribution, Applied Engineering in Agriculture, Volume 33, Issue 5, Pp: 641-653, 2017.

[12] Gayathri Devi Dr.K., Sowmiya N., Yasoda Dr.K., Muthulakshmi Dr.K., Kishore Mr.B.; Review on application of drones for crop health monitoring and spraying pesticides and fertilizers, Journal of Critical Reviews, Volume 7, Issue 6, Pp: $667-$ 672, 2020.

[13] Giles D.K., Billing R.C.; Deployment and performance of a UAV for crop spraying, Chemical Engineering Transactions, Volume 44, Pp: 307-312, 2015.

[14] Grella M., Gil E., Balsari P., Marucco P., Gallart M.; Advances in developing a new test method to asses spray drift potential from air blast sprayers, Spanish Journal of Agricultural Research, Volume15, Issue 3, Pp: 1-16, 2017.

[15] Ilker C., Mehmet D., Gurkan A., Erdal K.; Effect of air assistance on deposition distribution on spraying by tunnel-type electrostatic sprayer, African Journal of Agricultural Research, Volume 4, Issue 12, Pp: 1392-1397, 2009.

[16] Longo D., Manetto G., Papa R., Cerruto E.; Design and construction of a testing low-cost test bench for testing agricultural spray nozzles, Applied Sciences, MDPI, Volume 10, Issue 5221, Pp: 116, 2020.

[17] Luo L., Tang Y., Lu Q., Chen X., Zhang P., Zou X.; A vision methodology for harvesting robot to detect cutting points on peduncles of double overlapping grape clusters in a vineyard, Computers in Industry, Volume 99, Pp.:130-139, 2018.
[18] Mania E., Andreoli V., Cavalletto S., Cassardo C., Guidoni S., VICMOTO: physical modeling and numerical simulation applied to vineyard, BIO Web of Conferences, CO.NA.VI. 2018, Volume 13, Issue 02006, Pp: 1-5, 2019.

[19] Nieminen T.J., Sampo M.; Unmanned vehicle for agricultural and off-highway applications, Journal of Commercial Vehicles, SAE Transactions, Volume 102, Section 2, Pp: 450465, 1993.

[20] Qing T., Ruirui Z., Liping C., Min X., Tongchuan Y., Zhang Bin Z.; Droplets movement and deposition of an eight-rotors agricultural UAV in downwash flow field, Int. J. Agric. \& Biol. Eng., Volume 10, Issue 3, Pp: 47-56, 2017.

[21] Rao Mogili U.M., BVL Deepak B., Review on application of drone systems in precision agriculture, International Conference on Robotics and Smart Manufacturing (RoSMa2018), ScienceDirect Procedia Computer Science, Volume 133, Pp: 502-509, 2018.

[22] Raparelli T., Eula G., Ivanov A., Pepe G., Ricauda Aimonino D.; Preliminary analysis of interaction among gears, tines and soil in a rotary harrow, International Journal of Mechanics and Control (JoMac), Volume 20, Issue 1, Pp: 81-91, 2019.

[23] Raparelli T., Eula G., Ivanov A., Pepe G.; Force analysis in a three point-hitch mechanism of category 2 for agricultural tractors, International Journal of Mechanics and Control (JoMac), Volume 20, Issue 2, Pp: 123-133, 2019.

[24] Raparelli T., Pepe G., Ivanov A., Eula G.; Kinematic analysis of rotary harrows, Journal of Agricultural Engineering, Standard Issue, Volume 51, Issue 1, Pp: 9-14, 2020.

[25] Raparelli T., Ivanov A., Pepe G., Eula G.; Analysis of the energy consumption of a rotary harrow, Journal of Agricultural Engineering, Volume LII, Issue 1132, Pp: 1-9, 2021.

[26] Vallet A., Tinet C., Douzals J.P.; Effect of nozzle orientation on droplet size and droplet velocity from vineyard sprays, Journal of Agricultural Science and Technology B, Volume 5, Pp. 672678, 2015.

[27] Wen S., Zhang Q., Deng J., Lan Y., Yin X., Shan J.; Design and experiment of a variable spray system for unmanned aerial vehicles based on PID and PWM control, Applied Sciences, MDPI, Volume 8, Issue 2482, Pp:1-22, 2018.

[28] www.teejet.com/CMSImages/TEEJET_IT/docu ments/catalogs/cat51a-it.pdf 2014. accessed on: 16.09 .2021

[29] Yang F., Xue X., Cai C., Sun Z., Zhou Q.; Numerical simulation and analysis on spray drift movement protection unmanned aerial vehicle, Energies, MDPI, Volume 11, Issue 2399, Pp:1-20, 2018. 